\title{
Restorative Dentistry Joint Scientific Meeting 2019
}

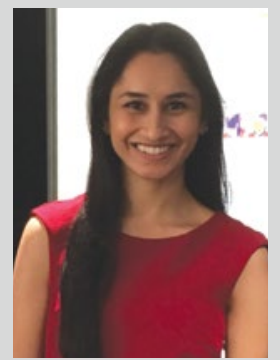

For the first time, the Brvitish Society of Restorative Dentistry (BSRD), the Specialty Registrars in Restorative Dentistry Group (SSRDG) and Restorative

Dentistry UK (RD-UK) came together to host a joint conference that took place from 21-22 November 2019 at the Science Gallery in London.

The aim of the conference was to bring together representatives from all disciplines of restorative dentistry to encourage collaboration. A fantastic trade show was present throughout the conference that enabled delegates to engage with a range of industry representatives.

Day 1 of the conference - 'If I knew then what I know now: Preventing and managing failures' - opened with a warm welcome to by Dr Sophie Watson, President of BSRD.

An energetic presentation by Dr Shazad Saleem followed, providing clarity on the management of patients with periodontitis in primary care and the most appropriate time for referral to secondary care. He helped to design 'Healthy Gums Do Matter', a toolkit that aims to explain how to approach periodontal disease management under the current NHS contract.

This was followed by an exhilarating lecture by Dr Lloyd Searson on 'The Seven Deadly Sins of the Dental Implant World, where he encouraged the audience not to read things in black and white and focus on clinical effectiveness. Professor Francesco Mannocci's talk about 'Endodontic Failures \& Pathways to Success' captured the audience's imagination and pushed us to consider subconscious bias and other limitations that affect treatment outcomes.

Mr Matthew Jarreat launched the afternoon session with a bold and enlightening presentation regarding the development of Managed Clinical Networks and Local Dental Networks for commissioning services in restorative dentistry in the South West of England, an area where specialist resources are limited.
Delegates were then introduced to three Clinical Excellence Networks (CEN) - for Hypodontia, Head and Neck Oncology and Cleft Lip and Palate - that facilitate continuous quality improvement for patient outcomes with an MDT approach.

Thursday evening saw the celebrities of the world of restorative dentistry dazzling the halls of the Science Gallery with access to a private viewing of the exhibition 'ON EDGE: Living in an Age of Anxiety'. The event was completed with a three-course dinner that left the attendees feeling indulged.

With a fresh start on Friday, delegates were welcomed by an introduction to the theme, 'Developmental dilemmas of the dentition and its management'. It did not disappoint, with some fantastic talks kicked off by Dr Mike Harrison's discussion of the genetic aspects of dental developmental defects. His wealth of knowledge, within dentistry and beyond, raised awareness of the issues to consider when treating patients with inherited conditions. Dr Serpil Djemal provided a brilliant and succinct overview of resin-bonded bridges, perfectly complemented by Professor Avi Banerjee's definitive lecture on adhesion. The final presentation was delivered by Lee Savarrio, who shared his wisdom and experience of the use of implants in hypodontia patients.

The afternoon consisted of an interactive discussion of treatment planning for hypodontia cases. It was fascinating to observe a panel of experts, chaired by Professor Martin Ashley, identify and debate the merits of multiple appropriate treatment plans to achieve successful outcomes for each patient - a most entertaining CEN!

The Restorative Dentistry Joint Scientific Meeting convenes at The Crowne Plaza in Glasgow, Scotland in March 2020, joining forces with a fourth organisation, the British Society of Prosthodontics (BSSPD), for the first time in conference history.

I would like to thank BSRD, SRRDG and $\mathrm{RD}-\mathrm{UK}$ for organising this rewarding and stimulating conference. I look forward to attending the joint meeting in March along with a host of new delegates.

By Sameera Kapadia, DCT3 in Restorative Dentistry, Liverpool University Dental Hospital
DENTISTS ON FILM

A Christmas Story 2

H. S. Brand of the Academic Centre for Dentistry Amsterdam, and film aficionado, returns with a special review of 'A Christmas story 2', a film directed by Brian Levant in 2012.

$\mathrm{T}$ he film takes place in 1946. Halfway through the film, Randy has to go to the dentist. While he shouts 'I don't want to go! No! Stop, he's evil!', Randy tries to prevent this by holding onto the railing of the stairs that lead to the dental office. Randy's mother pulls his arm and says reassuringly: 'He's a wonderful dentist, Randy'.

In the meantime, a voiceover says: 'Gunter Strassen, DDS. The most feared name in Lake County ... known to every kid in Hohman as the Butcher of Berwyn Avenue.'

Next, we see a foot operate the pedal of a belt-driven, gear angle handpiece. Meanwhile, the voiceover continues: 'The Butcher had a drill he pedalled with his foot. The Butcher had little use for such newfangled novelties as Novocain.'

The dentist puts on latex gloves and wears a large head mirror. He enters Randy's mouth with the handpiece and a dental mirror. While the dentist grins meanly, Ralph shouts out. This is heard by his mother in the waiting room. She looks up from her newspaper and through a semi-transparent glass door she sees her son struggling in the dental chair while the drilling continues. Ralph keeps screaming while the dentist mumbles 'Ah. Ah.' Ralph's mother looks anxious, and the dentist's receptionist says 'Sweet, isn't it?' The receptionist makes the sign of the cross and lowers her eyes, after which the scene

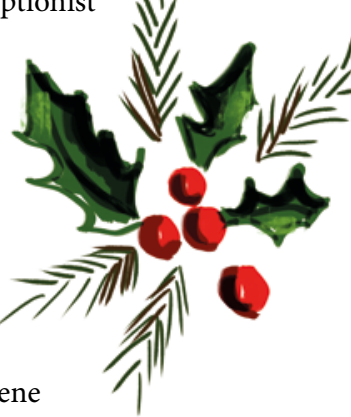
ends abruptly. 